\title{
Integrating Renewable Energy and Smart Grid Technology into the Nigerian Electricity Grid System
}

\author{
Emodi Nnaemeka Vincent, Samson D. Yusuf \\ Department of Technology Management Economics and Policy Program, College of Engineering, Seoul \\ National University, Seoul, South Korea \\ Email: icecube4ever2000@gmail.com
}

Received 30 June 2014; revised 3 August 2014; accepted 16 August 2014

Copyright (C) 2014 by authors and Scientific Research Publishing Inc.

This work is licensed under the Creative Commons Attribution International License (CC BY). http://creativecommons.org/licenses/by/4.0/

(c) (i) Open Access

\begin{abstract}
The electricity situation in Nigeria can be described as epileptic with no sign in view of improvement. This epileptic power situation affects the manufacturing, service and residential sectors of the economy which in turn affects the country's economic growth. Even with the recent reforms in the power sector, more than half of the country's population still lack access to electricity. The epileptic condition of the power sector can be attributed to the inadequate and inefficient power plants, poor transmission and distribution facilities, and outdated metering system used by electricity consumers. This paper attempts to present the way forward for the Nigerian poor electricity situation by reviewing the power sector as a whole and the renewable energy potentials. We identified the problems in the national grid and then proposed a smart grid model for the Nigerian power sector which will include renewable energy source. We believe that the content of this review paper will solve the poor epileptic condition of the power sector in Nigeria and also enable the proper integration of smart grid technology into the national grid.
\end{abstract}

\section{Keywords}

Epileptic Power, Power Sector, Smart Grid, Renewable Energy, National Grid

\section{Introduction}

Electricity is an important facet of any nation's development. In Nigeria, electricity is the pillar of its growth and development with roles in the nation's production of goods and services in the industrial sector as well as agriculture, health and education [1]. Nigeria, a county known as "the giant of Africa" is blessed with an abundant 
amount of fossil fuel and renewable energy resources, but the country is battling with an acute epileptic power situation. According to the World Bank data; only about $50.9 \%$ of Nigerians have access to electricity [2].

The just concluded World Economic Forum on Africa which took place in Abuja, Nigeria (ended on $9^{\text {th }}$ May, 2014) saw an investment boost to the tune of $\$ 68$ billion from foreign and domestic investors in the service and industrial sectors. Sadly, this investment will meet its "waterloo" if the Nigerian power situation does not improve. Nigeria's poor energy situation results from the national grid network with problems ranging from inefficient power plants which are few in numbers to lack of renewables to support peak load, physical deterioration of the long transmission lines to distribution facilities which are inadequately maintained, lack of communication facilities, illegal electricity connections and outdated meters used by the consumers [1]. However, this paper tends to address the research question: what is the way forward for the Nigerian poor electricity situation? In order to solve the above research question, the paper reviews the current electricity sector in Nigeria and the concept of smart grid technology. Furthermore, we suggest a future direction on the integration of smart grid into the Nigerian electricity grid network in conjunction with renewable energy.

This paper is divided into seven main sections: the first section is the introduction and the second is an overview of the power sector where we reviewed the history of the power sector and its various sectors which comprise of the generation, transmission and distribution after which we go into the regulatory agencies, key institutions and the current electricity situation in Nigeria. The third section focused on the renewable energy resource potential and the areas where they are located within the country and their possible application. The forth section introduces the smart grid technology while the fifth section discussed about the integration of smart gird technology into the Nigerian grid network and the various technological upgrades required to make the smart grid system in Nigeria possible. In the sixth section, we give our discussion and present a proposed smart grid model after which we outline some factors that may affect smart grid integration in Nigeria followed by a review on the Nigerian Energy Policy and finally the benefits of smart grid technology are presented. Our policy recommendation to facilitate the proper integration of renewables and smart grid technology into the Nigerian electricity grid system are given in section seven which also includes the conclusion to this paper.

We believe that this paper will contribute immensely to the possibility of smart grid and renewable integration into the Nigerian electricity grid.

\section{Overview of the Nigerian Power Sector}

\subsection{History}

In Nigeria, electricity generation rose from few kilowatts that were used in Lagos by the colonial masters when the first generating plant was installed in 1898 [3]. By the Act of Parliament in 1951, the Electricity Corporation of Nigeria (ECN) was established. Niger Dams Authority was set up in 1962 to develop hydroelectricity and was merged with ECN to form the National Electric Power Authority (NEPA) in 1972. Despite various effort by NEPA (which operated a monopolized market) to manage the power sector by providing electricity to the increasing population, it became clear that NEPA was losing the battle to meet up with the electricity demand in the 1990s. Hence, in 2001, the National Electric Power Policy (NEPP) was introduced to kick-off the power sector reform and this lead to several other reforms in the past years [4]. The NEPP in 2001 created the roadmap for Nigeria's Power Sector Privatization, but due to government bureaucracy; the policy was not signed into law until 2005. This signed document was the Electric Power Sector Reform (EPSR) Act in 2005 which was expected to level the playing ground for potential investors and improve the wellbeing of its citizens. The EPSR Act led to the incorporation of the Power Holding Company of Nigeria from NEPA, which was later defunct and divided into sub-sectors [3] [4].

\subsection{Sub-Sectors}

The power sector in Nigeria is divided into three major subsectors which are; Generation (NESI), Transmission (TCN) and Distribution (DISCOS).

\subsubsection{Generation}

The splitting of the power sector led to the formation of Nigerian Electricity Supply Industry (NESI) which currently has 23 grid-connected generating plants in operation with a total installed capacity of 10,396 MW and available capacity of $6056 \mathrm{MW}$. Thermal based installed capacity is 8457.6 MW with available capacity of 4996 
MW. Hydropower from three major plants accounts for 1938 MW of the total installed capacity with 1060 MW as available capacity. The generation segments of the Nigerian power sector are divided into [4]:

- Successor Generation Companies (Gencos): with six successor companies.

- Independent Power Producers (IPPs): they are owned and managed by the private sector and have three generating facilities.

- National Integrated Power Projects (NIPP): they are owned by the government and have 10 generating facilities.

\subsubsection{Transmission}

The splitting also formed the Transmission Company of Nigeria (TCN) which was a successor of the PHCN. It is made up of two departments namely System Operator and Market Operator. The transmission capacity is made up of about 5523.8 KM of $330 \mathrm{KV}$ lines and 6801.49 KM of $132 \mathrm{KV}$ lines [4].

\subsubsection{Distribution}

The third sub-sector which is the distribution comprises of eleven electricity distribution companies (DISCOS). The DISCOS are listed below in alphabetical order [4]:

- Abuja Distribution Company

- Benin Distribution Company

- Eko Distribution Company

- Enugu Distribution Company

- Ibadan Distribution Company

- Ikeja Distribution Company

- Jos Distribution Company

- Kaduna Distribution Company

- Kano Distribution Company

- Port Harcourt Distribution Company

- Yola Distribution Company

\subsection{Regulatory Agencies and Key Institutions}

We will now look at the various regulatory agencies and key institution in the power sector.

\subsubsection{Regulatory Agencies}

The regulatory agencies are [4]:

- The Federal Ministry of Power (FMP): an administrative arm of the federal government that deals with policy formulation and provides general direction to other agencies involved in the power sector.

- Nigerian Electricity Regulatory Commission (NERC): an independent regulatory agency mandated to regulate and monitor the Nigerian Power Sector and was established in 2005 by the EPSR Act.

- Energy Commission of Nigeria (ECN): was established in 1988 with a stator mandate for strategic planning and coordination of national policies in the field of energy.

- Rural Electrification Agency (REA): was established by the EPSR Act with the statutory functions of promoting, supporting and providing electricity access to rural and semi-urban areas of the country.

- Presidential Task Force on Power (PTFP): was set up in 2010 to drive the implementation of the reform of Nigeria's Power sector.

\subsubsection{Key Institutions}

The key institutions are [4]:

- Niger Delta Power Holding Company Limited (NDPHC): is owned by the three arms of the government (i.e. federal, state and local) with the responsibility for the implementation of the National Integrated Power Project (NIPP).

- Nigerian Bulk Electricity Trading PLC (NBET): also government owned and was established by the EPSR Act as an electric trading licensee that engages the purchase of electric power and ancillary services (from the independent power producers and the successor generating companies) and subsequent resale to distribution companies and eligible customers. 
- Operator of the Nigerian Electricity Market (ONEM): was licensed to function as a market operator for the wholesale electricity market of the Nigerian Electricity Supply Industry, with the responsibility of operation in the electricity market and settlement arrangements. A key function of the ONEM is the administration of metering system among generation, transmission and distribution companies.

- Nigerian System Operator (NSO): was licensed to provide system operation services to the Nigerian Electricity Supply Industry; its primary responsibility is the planning, dispatch and operation of the transmission system. Also, it's responsible for the security and reliability of the nation's electricity grid network.

- Gas Aggregation Company Nigeria Limited (GACN): was incorporated in 2010 for the purpose of stimulating growth of natural gas utilization in the Nigerian domestic market.

- National Power Training Institute of Nigeria (NAPTIN): was established in 2009 to serve as a focal point for human resource development and work-force capacity building, and also act as a research center on matters relating to power in Nigeria.

- Nigeria Electricity Liability Management Company Limited (NELMCO): was established in 2006 as a company limited by guarantee, to assume and manage the non-core assets, all liabilities and other obligations that would not be taken over by the successor companies.

\subsection{Current Electricity Situation}

Nigeria is faced with many electricity problems which range from generation, transmission to distribution and marketing. We will review this problems one after the other;

Generation: The total installed capacity of the currently generating plants in Nigeria as discussed earlier is 10,396.0 MW, but the available Capacity is less than 6056 MW as at December 2013. Seven of the twenty-three generation stations are over 20 years old and the average daily power generation is lower than the peak forecast for the current existing infrastructure. Through the planned generation capacity projects for a brighter future, the current status of power generation in Nigeria presents challenges, such as inadequate generation availability, delayed maintenance of facilities, insufficient funding of power stations, obsolete equipment, tools, safety facilities and operational vehicles, obsolete communication equipment, lack of exploration to tap all sources of energy from the available resources and low staff morale [5] [6].

Transmission: The current transmission system in Nigeria comprises $5523.8 \mathrm{~km}$ of $330 \mathrm{kV}, 6801.49 \mathrm{~km}$ of $132 \mathrm{kV}, 32$ No. 330/132 kV Substations with total installed transformation capacity of 7688 MVA. 105No. 132/33/11 kV Substations with total installed transformation capacity of 9130 MVA. The average available capacity on 330/132 kV is 7364 MVA and 8448 MVA on 132/33 kV. The Nigeria $330 \mathrm{KV}$ transmission grid is characterized by high power losses due to the very long transmission lines. Some of these lines include Benin—Ikeja West (280 km), Oshogbo—Benin (251 km), Oshogbo—Jebba (249 km), Jebba—Shiroro (244 km), BirninKebbi—Kainji (310 km), Jos—Gombe (265 km) and Kaduna— Kano (230 km) [6].

Power losses result in lower power availability to the consumers, leading to inadequate power to operate the appliances. Thus, the high efficiency of the power system is determined by its low power losses. Increased power demand pushes the power transmission and distribution networks to their upper limits and beyond, resulting to shortening of the life span of the network or total collapse [6] [7].

The Nigerian transmission system does not cover every part of the country. It currently has the capacity to transmit a maximum of about $6056 \mathrm{MW}$ and it is technically weak, thus very sensitive to major disturbances. Major problems associated with transmission systems include poor funding by the Federal Government, it is yet to cover many parts of the country, it's current maximum electricity wheeling capacity is 6,056 MW which is awfully below the required national needs, some sections of the grid are outdated with inadequate redundancies as opposed to the required mesh arrangement, regular vandalization of the lines, associated with low level of surveillance and security on all electrical infrastructure, technologies used generally deliver very poor voltage stability and profiles, there is a high prevalence of inadequate working tools and vehicles for operating and maintaining the network, there is a serious lack of required modern technologies for communication and monitoring, transformers deployed are overloaded in most service areas, inadequate of spare parts for urgent maintenance, poor technical staff recruitment, capacity building and training programme [5] [6].

Distribution and Marketing: In most regions in Nigeria, the distribution network is poor, the voltage profile is poor and the billing is inaccurate. As the department, which inter-faces with the public, the need to ensure adequate network coverage and provision of quality power supply in addition to efficient marketing and customer service delivery cannot be over emphasized. Some challenges identified are, weak and inadequate net- 
work coverage, overloaded transformers and bad feeder pillars, substandard distribution lines, poor billing system, unwholesome practices by staff and very poor customer relations, inadequate logistic facilities such as tools working vehicles, poor and obsolete communication equipment, low staff morale and lack of regular training, insufficient funds for maintenance activities [5] [6].

Power Deficit: The total installed capacity of generating plants in Nigeria is 10,390 MW with available capacity less than $6056 \mathrm{MW}$, but power generation has been below $4500 \mathrm{MW}$. Using the rule of Thumb, where $1000 \mathrm{MW}$ is for $1,000,000$ people and the Nigerian population is $174,567,539$ [8], we should have about 174,508 MW for the Nigerian people but with the power generation that has not exceeded $4500 \mathrm{MW}$, we can say that Nigeria has a power deficit of 170,008 MW. Surprisingly, Nigeria is still growing at an amazing 6\% - 8\% [8] and the nation is doing so without almost no power (from the national grid) compared to other rapidly growing nations like South Africa with a population of about 50 million people (in real sense, less than a third of the Nigerian population) and still generates over 45,000 MW of electricity.

The map of the current Nigerian national grid system is shown in Figure 1 below [9].

\section{Renewable Energy Resources}

The renewable energy resources in Nigeria are as enormous as they are diverse. The summary of the renewable energy potentials are given in Table 1 [9].

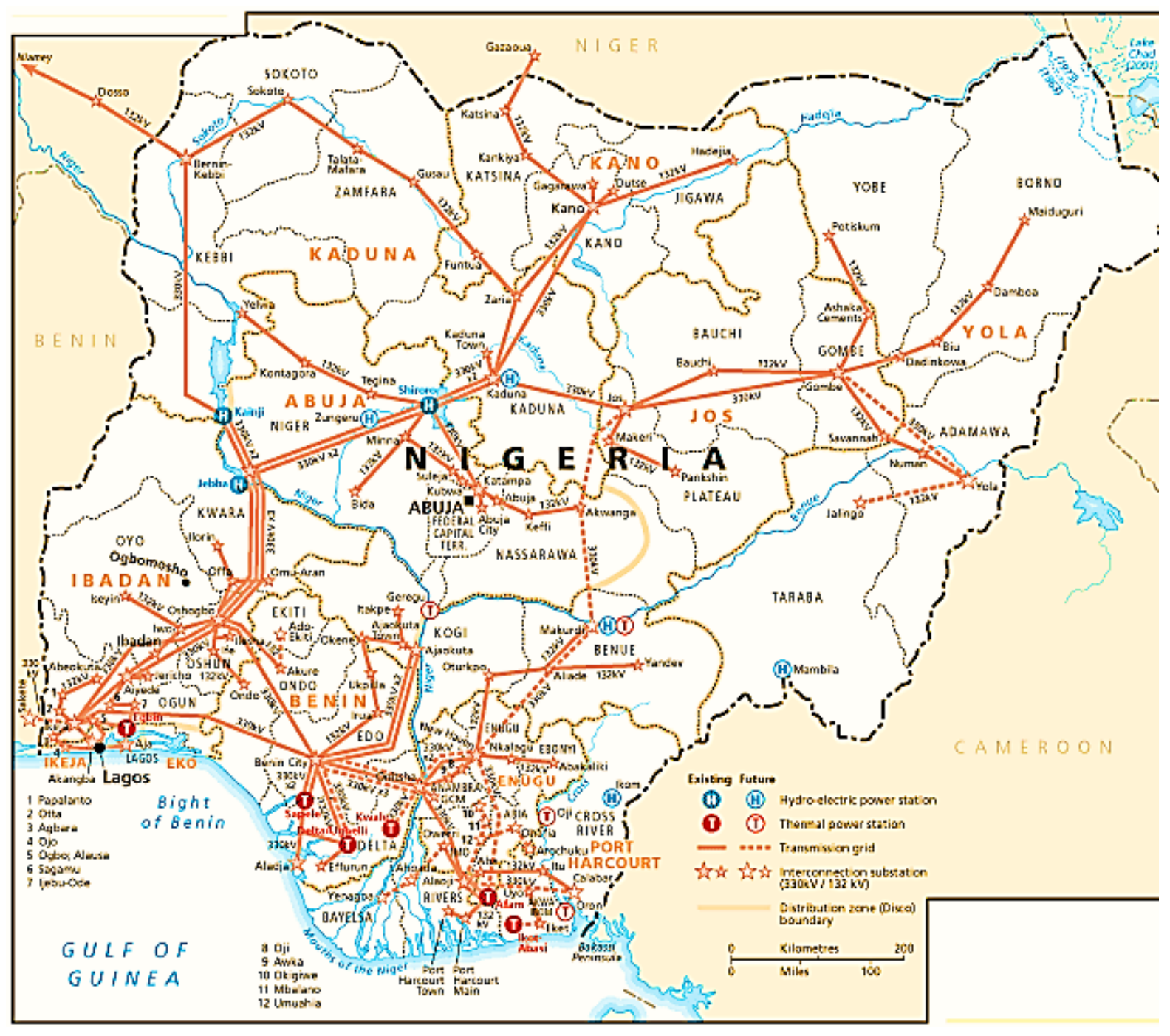

Figure 1. The Nigerian national grid system. 
Table 1. Renewable energy resources.

\begin{tabular}{|c|c|c|}
\hline \multicolumn{2}{|c|}{ Renewable Energy Source } & Capacity \\
\hline \multicolumn{2}{|c|}{ Small Hydropower } & $3500 \mathrm{MW}$ \\
\hline \multicolumn{2}{|c|}{ Large Hydropower } & $11,250 \mathrm{MW}$ \\
\hline \multicolumn{2}{|c|}{ Wind } & $2-4 \mathrm{~m}^{2}$ annually at $10 \mathrm{~m}$ height \\
\hline \multicolumn{2}{|c|}{ Solar Radiation } & $3.5-7.0 \mathrm{KMh} / \mathrm{m}^{2} /$ day \\
\hline \multirow{3}{*}{ Biomass } & Fuel Wood & $13,071,464$ hectares of forest and woodland \\
\hline & Animal Waste & 61 million tons/year \\
\hline & Crop Residue & 83 million tons/year \\
\hline
\end{tabular}

Source: Energy Commission of Nigeria, 2005.

\subsection{Solar Energy}

Nigeria is located within the region of high sunshine belt between longitude $3^{\circ}$ and $14^{\circ}$ east of Greenwich and latitude $4^{\circ}$ and $14^{\circ}$ north of the equator with a land area of $923,768 \mathrm{~km}^{2}$ [10]. The mean annual average of total solar radiation varies from about $3.5 \mathrm{kWh} / \mathrm{m}^{2} /$ day in the coastal regions to about $7 \mathrm{kWh} / \mathrm{m}^{2} /$ day along the semi-arid areas in the Northern border region. On the average, the country receives solar radiation at the level of about $19.8 \mathrm{MJ} / \mathrm{m}^{2} /$ day. Average sunshine hours are estimated at 6 hrs per day. Solar radiation is fairly well distributed. The minimum average is about $3.55 \mathrm{kWh} / \mathrm{m}^{2} /$ day in Katsina in the far North during the month of January and $3.4 \mathrm{kWh} / \mathrm{m}^{2} /$ day for Calabar in the Southeastern region around August and the maximum average is $8.0 \mathrm{kWh} / \mathrm{m}^{2} /$ day for Nguru in the Northeast during the month of May [1].

At a medium radiation intensity of $5 \mathrm{KWh} / \mathrm{m}^{2} /$ day and convention efficiency and if solar collectors modules were employed to cover $1 \%$ of land areas in Nigeria will generate approximately the daily energy equivalent of 192,000 MW of energy from a gas power plant working at full capacity for 24 hours a day [10] [11].

Solar electricity may be used for power supply to remote villages and locations not connected to the national grid. It may also be used to generate power for feeding into the national grid. Other areas of application of solar electricity include low and medium power application such as: water pumping, village electrification, rural clinic and schools power supply, vaccine refrigeration, traffic lighting and lighting of road signs [1]. The yearly average of daily sun in Nigeria is shown in Figure 2 [12].

\subsection{Biomass Energy}

Nigeria's biomass energy resources can be identified as fuel wood with capacity of about 13 million hectares of forest and wood land, animal waste is about 61 million tons/year and crop residue is currently limited to thermal application as fuel for cooking and crop drying. However, these biomass resources could be utilized as fuel for small scale industries to support electricity in the national grid [9].

\subsection{Hydropower}

Nigeria is reasonable endowed with large rivers and some few natural falls. Small rivers and streams also exist within the present split of the country into eleven river basin authorities. Studies have shown that the country possesses potential hydro-energy resources along her numerous river systems consisting of a total of 70 micro dams, 126 mini dams and 86 small sites [13]. The total exploitable potential of the country's large hydropower is estimated to about 11,250 MW while the small hydropower stands at $3500 \mathrm{MW}$ [9]. These rivers, waterfalls and streams with high hydropower potential, if properly harnessed will lead to decentralized use and provide the most affordable and accessible option to off-grid electricity service especially to the rural communities [8]. Figure 3 shows the various water ways in Nigeria [14].

\subsection{Wind Energy}

Wind is produced by the uneven heating of the earth's surface by the sun and its resultant pressure inequalities. Wind energy potential varies with wind speed and is available in Nigeria at annual average speeds of about 2.0 $\mathrm{m}^{2}$ at the coastal region and $4.0 \mathrm{~m}^{2}$ at the northern region of the country. Assuming an air density of $1.1 \mathrm{~kg} / \mathrm{m}^{3}$, 
Yearly average of daily sums of g lobal horizontal irradiation

(Helio Clim-1/PVGIS data, period 1985-2004)

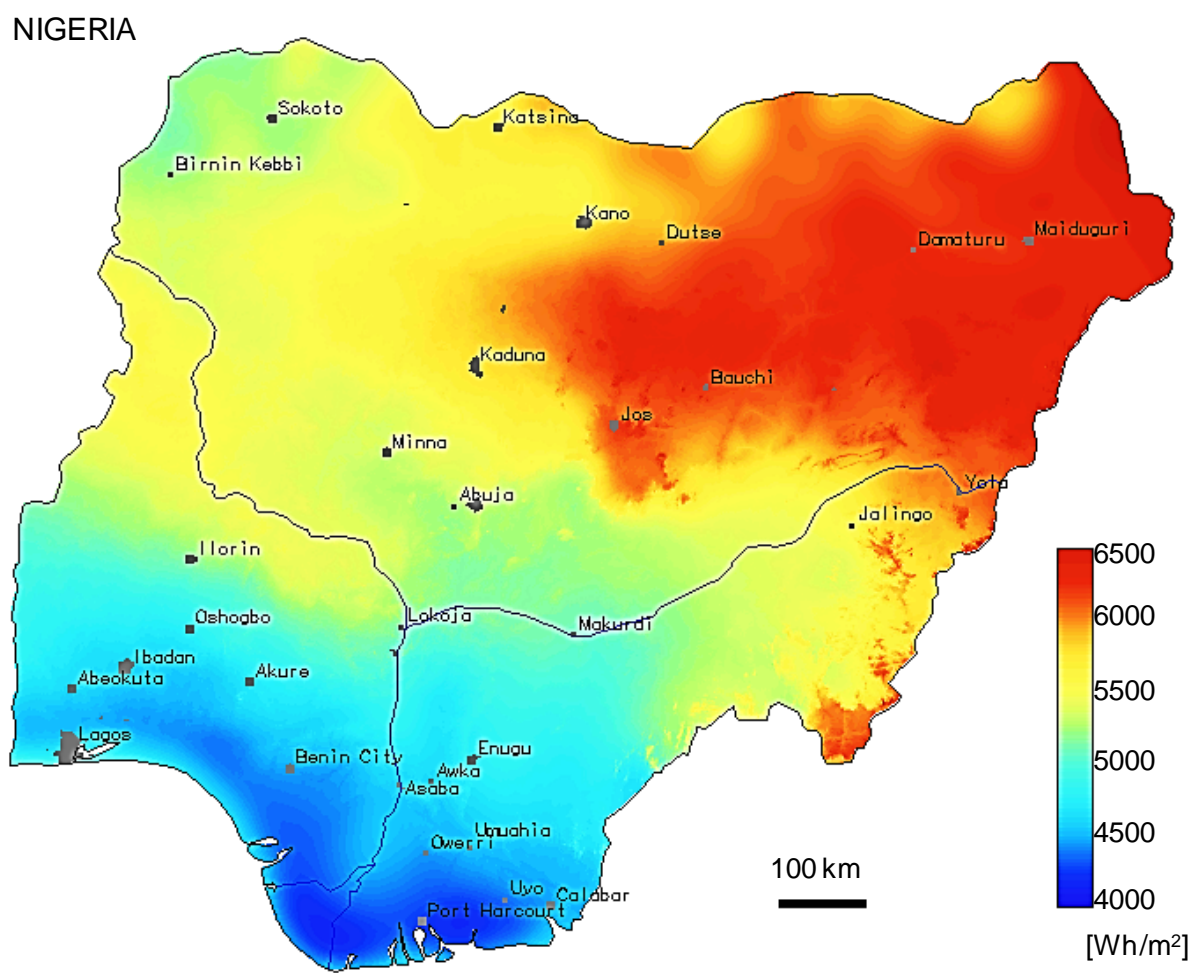

PVGIS (c) European Communities 2002-2006 Helio Clim-1 (c) Ecole des Mines de Paris/Armines 2001-2006

http://re.jrc.cec.eu.int/pvgis/pv/ http://www.soda-is.com/

Figure 2. The Yearly average of daily sun in Nigeria.

wind energy intensity, perpendicular to the wind direction, ranges between $4.4 \mathrm{~W} / \mathrm{m}^{2}$ at the coastal areas and $35.2 \mathrm{~W} / \mathrm{m}^{2}$ at the far northern region [1].

Various wind energy conversion systems like wind turbines, wind generators, wind plants, wind machines, and wind dynamos are devices which convert the kinetic energy of the moving air to rotary motion of a shaft, that is, mechanical energy. The technologies for harnessing this energy have, over the years been tried in the northern parts of the country, mainly for water pumping from open wells in many secondary schools of old Sokoto and Kano States as well as in Katsina, Bauchi and Plateau States. It has been reported that an average annual wind speed of not less than $5 \mathrm{~m} / \mathrm{s}$ at a height of $10 \mathrm{~m}$ above ground level is the feasible speed for the exploitation of wind energy at today's cost. In Figure 4 we can see the various wind energy location across the country [15].

\section{Smart Grid Technology}

Various authors, government organization and bodies have given numerous definitions of smart grid. A smart grid can be defined as an upgraded electricity grid network enabling two-way information and power exchange between suppliers and consumers, due to the pervasive incorporation of intelligent communication monitoring and management systems [16]. The US Department of Energy (DOE) defined smart grid as a system that will incorporate digital technology to improve reliability, efficiency and security of the electric system [17].

According to the International Energy Agency Technology Roadmap Smart Grid; a smart grid is an electricity network that uses digital and other advance technologies to monitor and manage the transport of electricity from all generation sources to meet the varying electricity demand of end-users. The smart grid will organize various capabilities and needs of the grid operators, generations, end-users and electricity market stakeholders to operate all the parts of the system as efficiently as possible, reducing environmental impacts and cost while improving system reliability, resilience and stability [18]. Besides the smart grid being able to match supply with demand, 


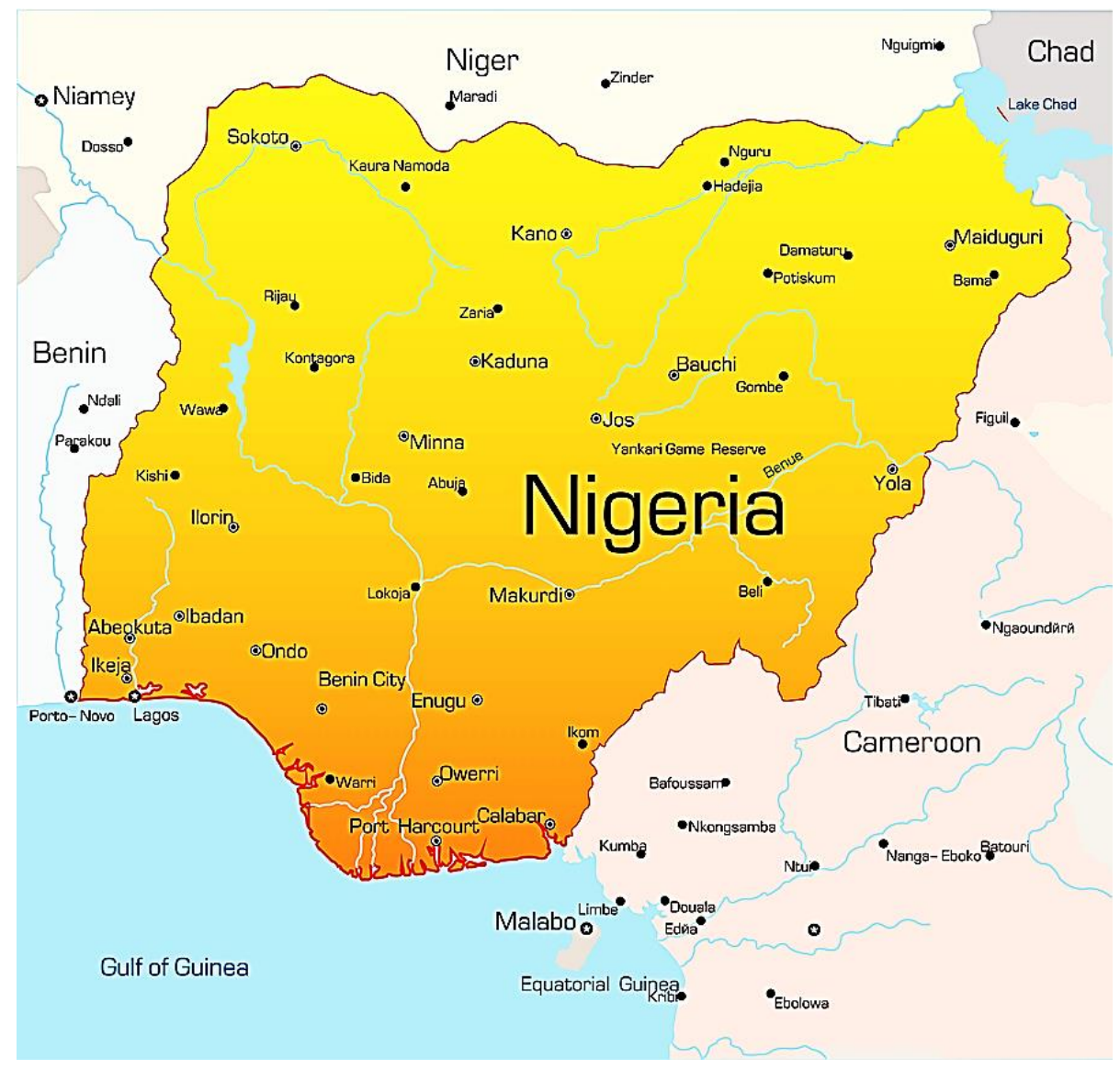

Figure 3. Waterways in Nigeria.

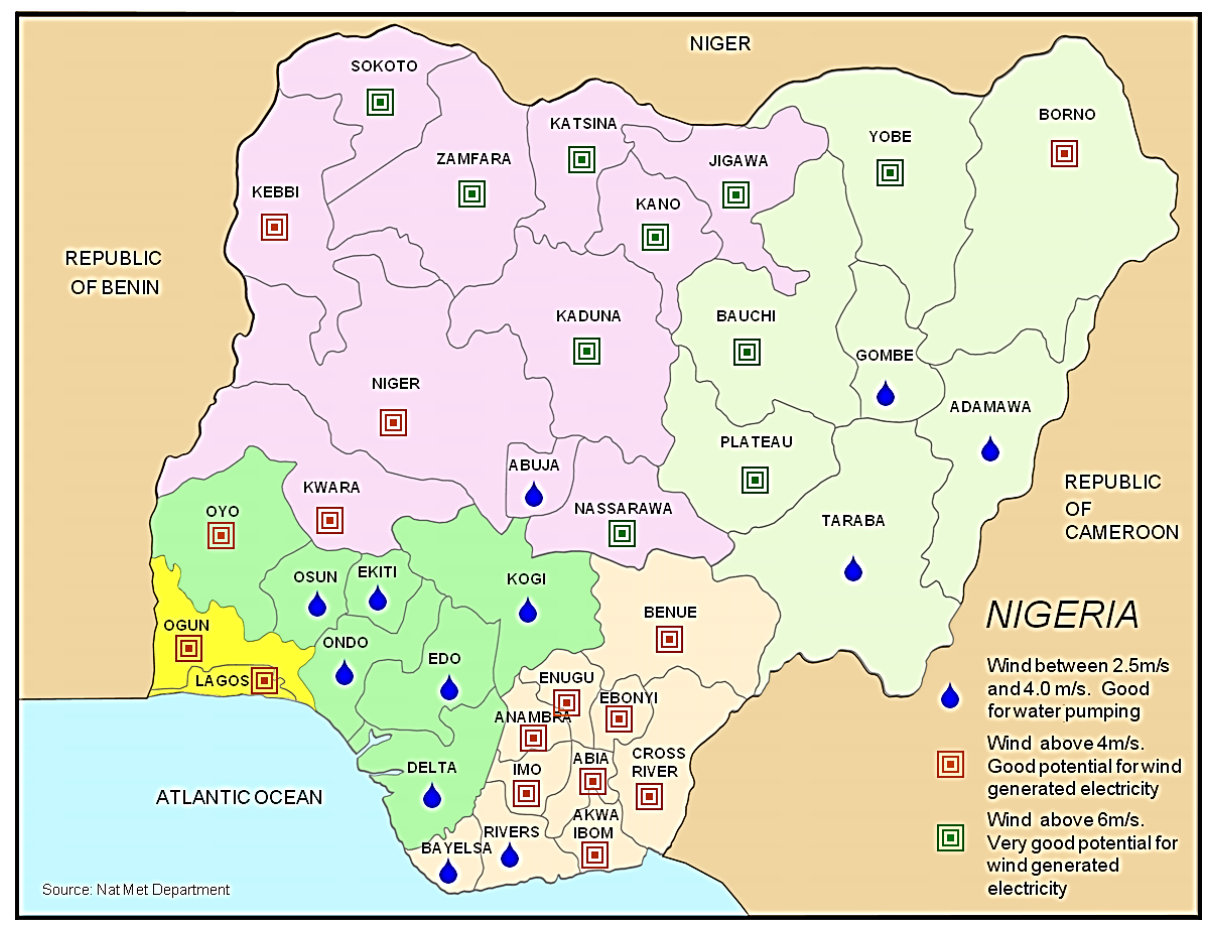

Figure 4. Wind energy location in Nigeria. 
it will also reduce the emission of greenhouse gases (GHG) by reducing the heavy dependence on fossil fuel plants through the integration of renewables which will make the system flexible and also electricity use will be more efficiently utilized.

\subsection{Wide Area Monitoring and Control}

Real-time monitoring and display of power system components and performance, across interconnections and over large geographic areas, help system operators to understand and optimize power system components, behavior and performance. Advanced system operation tools avoid blackouts and facilitate the integration of variable renewable energy resources. Monitoring and control technologies along with advanced system analytics-including wide area situational awareness (WASA), wide-area monitoring systems (WAMS), and wide-area adaptive protection, control and automation (WAAPCA) — generate data to inform decision making, mitigate widearea disturbances, and improve transmission capacity and reliability [18].

\subsection{Information Communication Technology Integration}

Underlying communications infrastructure, whether using private utility communication networks (radio networks, meter mesh networks) or public carriers and networks (Internet, cellular, cable or telephone), support data transmission for deferred and real-time operation, and during outages. Along with communication devices, significant computing, system control software and enterprise resource planning software support the two-way exchange of information between stakeholders, and enable more efficient use and management of the grid [18].

\subsection{Renewable and Distributed Generation}

Integration of renewable and distributed energy resources-encompassing large scale at the transmission level, medium scale at the distribution level and small scale on commercial or residential building can present challenges for the dispatchability and controllability of these resources and for operation of the electricity system. Energy storage systems, both electrically and for thermally based, can alleviate such problems by decoupling the production and delivery of energy. Smart grids can help through automation of control of generation and demand (in addition to other forms of demand response) to ensure balancing of supply and demand [18].

\subsection{Transmission and Enhancement Application}

There are a number of technologies and applications for the transmission system. Flexible AC transmission systems (FACTS) are used to enhance the controllability of transmission networks and maximize power transfer capability. The deployment of this technology on existing lines can improve efficiency and defer the need of additional investment. High voltage DC (HVDC) technologies are used to connect offshore wind and solar farms to large power areas, with decreased system losses and enhanced system controllability, allowing efficient use of energy sources remote from load centers. Dynamic line rating (DLR), which uses sensors to identify the current carrying capability of a section of network in real time, can optimize utilization of existing transmission assets, without the risk of causing overloads. High-temperature superconductors (HTS) can significantly reduce transmission losses and enable economical fault-current limiting with higher performance, though there is a debate over the market readiness of the technology [18].

\subsection{Distribution Grid Management}

Distribution and sub-station sensing and automation can reduce outage and repair time, maintain voltage level and improve asset management. Advanced distribution automation processes real-time information from sensors and meters for fault location, automatic reconfiguration of feeders, voltage and reactive power optimization, or to control distributed generation. Sensor technologies can enable condition- and performance-based maintenance of network components, optimizing equipment performance and hence effective utilization of assets [18].

\subsection{Advance Metering Infrastructure}

Advanced metering infrastructure (AMI) involves the deployment of a number of technologies-in addition to advanced or smart meters that enable two-way flow of information, providing customers and utilities with data 
on electricity price and consumption, including the time and amount of electricity consumed. AMI will provide a wide range of functionalities which will include; Remote consumer price signals, ability to collect, store and report customer energy consumption data for any required time intervals or near real time, improved energy diagnostics from more detailed load profiles, ability to identify location and extent of outages remotely via a metering function that sends a signal when the meter goes out and when power is restored, remote connection and disconnection, losses and theft detection, ability for a retail energy service provider to manage its revenues through more effective cash collection and debt management [18].

\subsection{Customer-Side System}

Customer-side systems, which are used to help manage electricity consumption at the industrial, service and residential levels, include energy management systems, energy storage devices, smart appliances and distributed generation. Energy efficiency gains and peak demand reduction can be accelerated with in-home displays/ energy dashboards, smart appliances and local storage. Demand response includes both manual customer response and automated, price-responsive appliances and thermostats that are connected to an energy management system or controlled with a signal from the utility or system operator [18].

Figure 5 shows the smart grid technology areas but this excludes the Electric Vehicle (EV) charging infrastructure but this could also be integrated in the future.

\section{Smart Grid Integration into the Nigerian Grid Network}

It is important to note that some technologies have been employed in the Nigerian grid system that can be upgraded to improve the "smartness" of the grid.

\subsection{Contradiction between the Two Grid Systems}

Some contradictions between the Nigerian grid system and smart grid system are given in Table 2 [6].

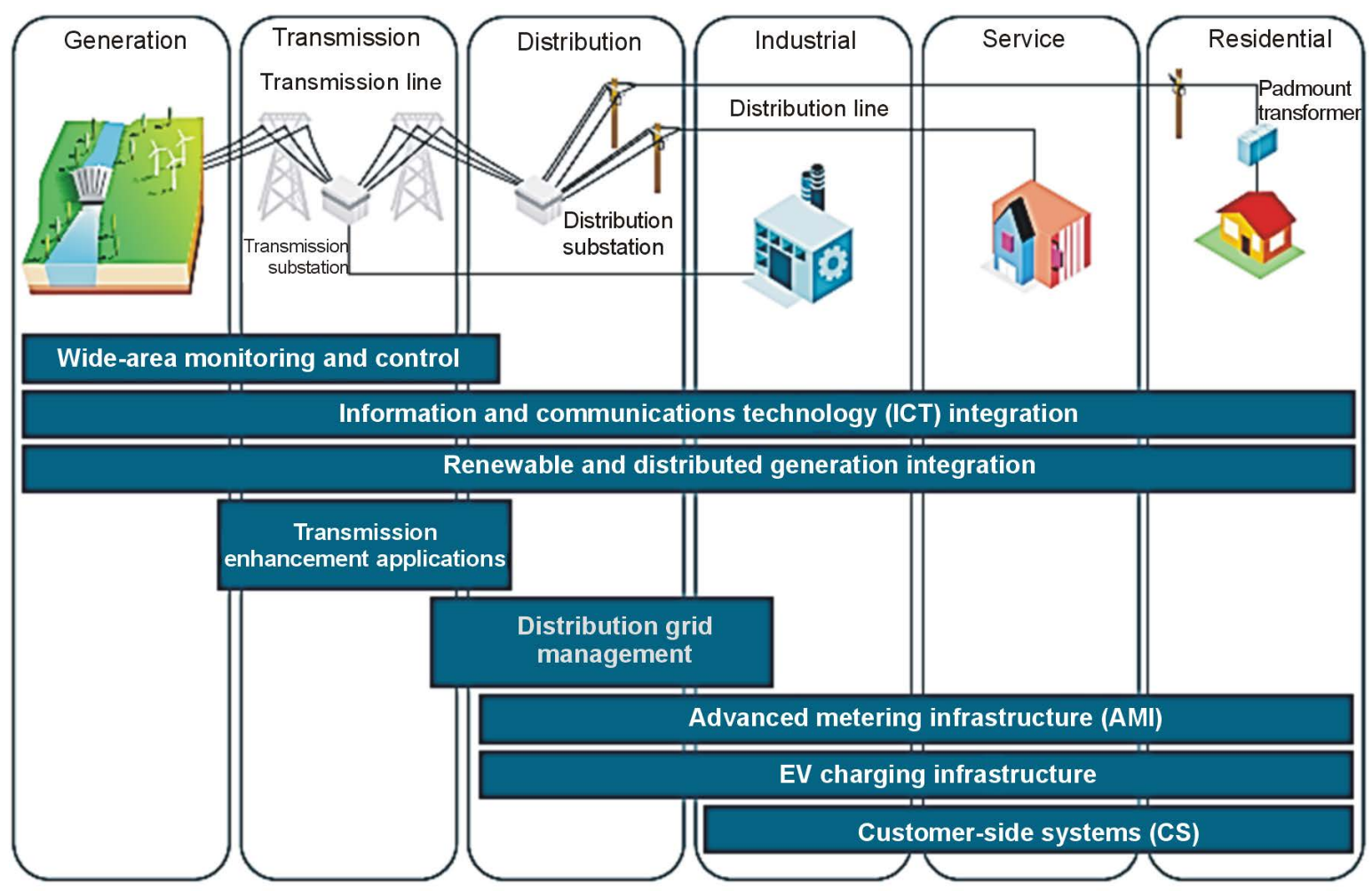

Source: Technology categories and descriptions adapted from NETL, 2010 and NIST, 2010.

Figure 5. Smart grid technology areas [18]. 
Table 2. Areas of Contradictions between the two grids.

\begin{tabular}{|c|c|c|}
\hline Areas & Nigeria Grid System & Smart Grid \\
\hline Generation & Majorly centralized stations & Centralized and distributed \\
\hline Transmission/Distribution line losses & $\begin{array}{c}\text { Above ten percent }(10 \%) \text { loss of the total } \\
\text { power in the transmission/distribution lines. }\end{array}$ & $\begin{array}{l}\text { About two percent }(2 \%) \text { loss of } \\
\text { the total power in the } \\
\text { transmission/distribution lines. }\end{array}$ \\
\hline System topology & Radial; generally one-way power flow & $\begin{array}{l}\text { Closed network; multiple power } \\
\text { flow pathways }\end{array}$ \\
\hline Operation and maintenance & Manual equipment checks. & $\begin{array}{l}\text { Remote monitoring, predictive, } \\
\text { time-based maintenance }\end{array}$ \\
\hline Reliability & $\begin{array}{c}\text { Prone to failures and cascading outages; } \\
\text { essentially reactive }\end{array}$ & $\begin{array}{l}\text { Automated, pro-active protection; } \\
\text { prevents outages before they start }\end{array}$ \\
\hline Power flow control & Limited & Comprehensive, automated \\
\hline Restoration following disturbance & Manual & Self-healing \\
\hline Communications & None or one-way; typically not real-time & Two-way, real-time \\
\hline Metering & Mainly electromechanical & $\begin{array}{l}\text { Digital (enabling real-time pricing } \\
\text { and net metering) }\end{array}$ \\
\hline Customer choice & Few customer choices & Many customer choices \\
\hline
\end{tabular}

\subsection{Integration}

The following explains the various enhancements needed in order to fully integrate the smart grid network in the Nigerian electricity grid system;

\subsubsection{Wide Area Monitoring and Control}

If sensory equipment like Phasor Measurement Units (PMU), strain gauge, infrared sensors, magnetic sensors and accelerometers are integrated into the Nigerian grid system will ensure proper monitoring and enable the system to automatically adapt and respond to changing conditions. Also, distribution devices will become intelligent remote on communication networks providing data collected through sensors back to operations control centers. Current technology on the national grid does not monitor power flows throughout the distribution grid because measurements are usually only available at the distribution substations. The sensors will also be able to collect information. Other types of wide area monitoring and control equipment that can also be mounted as mentioned in Section 4 include: Advance system operator tools, wide area situation awareness (WASA), Wide Area Monitoring System (WAMS) and Wide Area Adaptive Protection, Control and Automation (WAAPCA). The defunct Power Holding Company of Nigeria (PHCN) introduced Supervisory Control and Data Acquisition Systems (SCADA) to its power system to enable data monitoring and data collection of the generating stations. Other useful software includes GridLAB-D, Oracle Utilities Meter Data Management, Distribution Management System (DMS), and Visualizing Energy Resources Dynamically on Earth (VERDE) [19] [20].

\subsubsection{Storage Devices}

Energy storage devices like Hybrid Air Conditioning systems which come with lithium battery and inverter can convert electrical energy to thermal energy and store it. This is more economical than storing electricity in batteries. Such storage capabilities will be needed to grow the alternative energy sources, where unstable power flow from renewable energy plants such as wind and solar farms can be stored and better controlled. It can also supply power to the grid when it goes into island mode [18].

\subsubsection{Transmission Enhancement}

Equipment typically found in Transmission Company of Nigeria (TCN) substations includes the following: switch gears, high rupturing capacity fuses (HRC), air-cored ring shielded reactors, lightening arresters, circuit breakers, power transformers, isolators, and bus bars, among other items, while the network components include power lines, cables, circuit breakers, switches, transformers, large size conductors, steel lattice towers, steel tubular poles, wooden poles, earthing equipment. In Nigerian transmission power system, it will become impor- 
tant to fully utilize the existing transmission facilities instead of building new power plants and transmission lines that are costly to implement and involve long construction times. Flexible Alternating Current Transmission Systems (FACTS) controllers can be introduced in power systems to solve the above problems. FACTS make it possible to control the voltage magnitude of a bus, active and reactive power flows through transmission line of a power system. Line sensors can also be introduced to monitor real time situations of the Network [18].

\subsubsection{Distributed Generation (Renewables and Micro-Grid)}

As previously discussed in Chapter 2 of this article, Nigeria's electricity generating facilities are mainly thermal power plants and large centralized hydro plants scattered across the country. However, electricity must have to get to the users irrespective of where they reside. We also examined the renewable energy resources in Nigeria (Chapter 3), which is abundant in nature and yet not fully tapped. The integration of renewable energy into the national grid is one of the most important areas for infrastructure upgrades.

Considering the high variability and unpredictability of generation from renewable energy sources, the power generated can be safely absorbed in the grid if the frequency is maintained in an appropriate range. Frequency Support Ancillary Service (FSAS) can be used to complement the daily changes in the renewable generation. In the future, based on the renewable forecast for the day, a dispatch schedule for FSAS can be prepared such that the variation in the renewable energy generation can be absorbed easily. In other words, FSAS can be used as a mechanism to facilitate renewable energy integration by reducing the impact of variable generation [21].

Micro-grids can be utilized as a framework of system that can reduce the negative effect of power fluctuation on existing power systems, simultaneously pursuing the coexistence of environmental and supply, and existing power system and distributed power generation. They can also be considered to be flexible load. It keeps the power demand and supply balance by connecting to the external power system for maintenance of frequency and voltage. Micro-grid operators buy power through tie-line from the utility company when power in the micro-grids is deficient, and sell power when the power generated is in excess [6] [22].

\subsubsection{Advanced Metering Infrastructure}

In the past, electromechanical meters are used by consumers of the defunct Power Holding Company of Nigeria, they had mechanical parts that spin as electricity is consumed in the premises, and they show usage readout on small dials that a utility meter reader reads while on the property of your home. Presently in Nigeria, prepaid meters have been introduced in an effort to provide more efficient service for electricity consumers whereby the buy prepaid cards according to what they can afford [6] [22].

The prepaid meter disconnects from the national grid network once the available credit on the card runs out due to the customer home use. Smart meters, otherwise referred to as Advanced Metering Infrastructure (AMI) or two-way meters are electric meters which utilize two-way communications between the meters and the utility company and enable two way power flows to consumers. This technology enables users to monitor their consumption patterns in real-time and enables features which include time stamping of meter data, outage reporting, communication into the customer premise and on-request reads. It also enables the consumer to supply power back to the grid from solar panels or other local renewable sources and enables load management by responding to fluctuations in demand [6] [22].

\subsubsection{Customer-Side System}

With the introduction of smart grid technologies in Nigeria, customer-side system will also be introduced to aid in electricity management by residential, service and industrial customers, the include; smart appliances, energy storage devices, energy management devices and energy applications for smart phones and tablets.

\section{Discussion, Factors, Energy Policy and Benefits}

\subsection{Discussion}

So far we have briefly reviewed the Nigerian electricity sector, identify the current electricity situation and renewable energy resources available within its boundary. We also reviewed the concept of smart grid technology and then applied the various technological enhancements that could be integrated into the Nigerian electricity grid system. Smart grid as we know it is more of an enhancement to the electricity grid whereby there is an interaction between the producers and consumer due to the introduction of information and communication tech- 
nology (ICT) as shown in Figure 5.

In the current Nigeria national grid system as shown in Figure 6, we can see that electricity flows in one direction, i.e. from the producer which is the Nigeria Electricity Supply Industry (NESI) to the Transmission Company of Nigeria (TCN) to the Distribution Company of Nigeria (DISCOS) then to the final consumers. In Figure 6, we can observe that the communication in the grid is between the TCN and its substation, the DISCOS and its substation, and finally the Nigerian Electricity Regulatory Commission (NERC) which connects the consumers and the DISCOS. As discussed earlier in Section 2, the current national electricity grid lacks properly maintained generating facilities coupled with lack of renewable energy resource to support peak demand and diversify power generation, this we can see in Figure 6, other problems include long poorly maintained transmission lines and lack of communication equipment in the both the transmission and distribution centers. The last problem is the metering system used by the electricity consumers.

In our proposed smart grid system (Figure 7), we could see that a lot of ICT enhancement has been added to make the grid "smarter" than it was in Figure 6. We started by introducing the nuclear power plants which will be introduced in the near future (see Section 6.2), renewables and energy storage system (ESS) were also introduced into the national grid system to enhance distributed generation which will be controlled by Frequency Support Ancillary Service (FSAS). We also observed in Figure 7 that different communication device have been placed around the grid network to facilitate real time data flow within the grid through the communication lines.

Another important feature in Figure 7 is the inclusion of mini grid system which will be located in areas that are off-grid. The final observation in Figure 7 is the include the addition of solar power, energy storage system and smart meter for residential, commercial and industrial customers, these will enable them to be more energy efficient and they will be able to sell back power to the grid, this will make them to be fully involved in the power sector as both consumers and producers.

\subsection{Factors That May Affect Smart Grid Integration in Nigeria}

Smart grid is possible in Nigeria as we have previously discussed in the previously, the next step is to identify the factors that may affects its integration in Nigeria;

\section{Vandalism of transmission lines and distribution equipment:}

The vandalisation of the transmission infrastructures and the distribution equipment has been a common occurrence, even before the on-going power sector reforms. Most times, the sabotage is blamed on the power brokers who imports power generators. Vandalism is one of the current challenges that will likely translate hinder or cripple the integration of Smart grid in Nigeria [2].

Poor maintenance of existing power system:

Over the years of electricity infrastructures in Nigeria, poor maintenance has been one of the major causes of epileptic nature of power supply, even when generation capacity rises and Smart grid is introduced; its utilization is limited by the malfunctioning of the transmission and distribution infrastructure. The only known maintenance carried out by the power sector workers is fault clearing while scheduled maintenance for healthy function and life extension of such infrastructure is non-existent [2].

Information, research and development:

There has been a lack of publicly available data and information on the clean energy potential in Nigeria and potential new players in the sector lack the basic information upon which to make business decisions. The generation of reliable information and effective management of such information are paramount for good planning and implementation. On the issue of $\mathrm{R} \& \mathrm{D}$, much has not been done to improve research into possible ways of integrating smart grid technology and also proper educational training to Nigerian engineers on smart grid.

\section{Low generating capacity:}

The country's present overdependence on gas fired generation plants has resulted in supply disruptions in times of gas shortages which are very common occurrences. This, coupled with the high vulnerability of Nigerians' electricity network system has so far contributed to the unreliability of the overall system. Commercial electricity generation in Nigeria currently comes from power stations and various independent power projects around the country generating available electricity capacity of $6056 \mathrm{MW}$ which translates to 28 watts per capita power capacity. This is grossly inadequate even for domestic consumption. For Nigeria to meet up its energy needs, it requires per capita power capacity of 1000 watts or power generating/handling capacity of 170,000 MW [10]. 


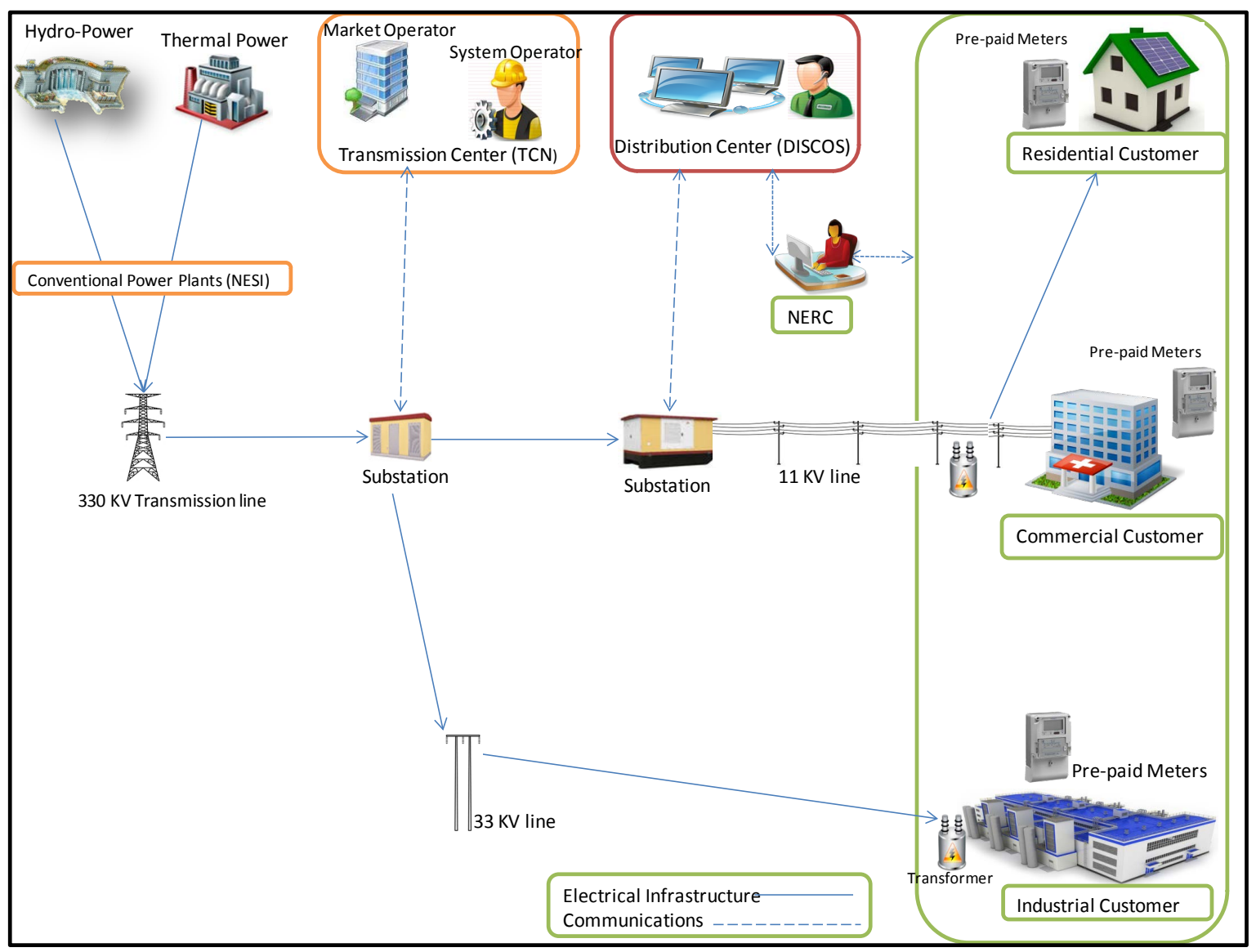

Figure 6. The present Nigeria national grid system.

\section{Lack of institutional arrangement:}

The lack of implementation of clean energy policies and the lack of coordination among relevant government agencies has created distortions and makes clean energy development more difficult. Inter-ministerial rivalries, overlap of mandates and outright protection of space often send wrong signals to potential investors. The absence of a clear political vision and leadership, weak regulatory institutions and inadequate human capacity, coupled with limited funding by government, all add up to make Nigeria's renewable energy market look dwarfed compared to that of much smaller countries like Kenya. Currently, there is little hope for a quick transition to a green economy. No program to equip rural women with small-scale renewable energy education and knowledge. The proposed Climate Change Commission under the Presidency would have the potential to increase synergies across ministries, and government agencies at the federal, state and local levels. However, the Bill to establish the Commission remains unsigned by the President. All these will have negative effect on smart grid if the technology is to be introduced in Nigeria [11].

\section{Corruption:}

The menace of corruption has set the nation backward among her contemporaries. Corruption is a ubiquitous practice that has ravaged every sector of the economy in Nigeria, including the power sector. Reform is not spared from its venom. The instances of corruptions in the power sector are numerous and provoking to even discuss about.

\section{Consumer behavior:}

Due to the unreliable nature of power supply, consumers developed a poor power usage methodology. This method tends towards wasting energy instead of making proper use of it. For instance most consumers don't use energy saving bulbs and rarely switch off portions of energy that are not in use. The inclusion of smart metering will curtail these wastages because energy usage will become more interactive and cost effective, making people purchase what they really need. 


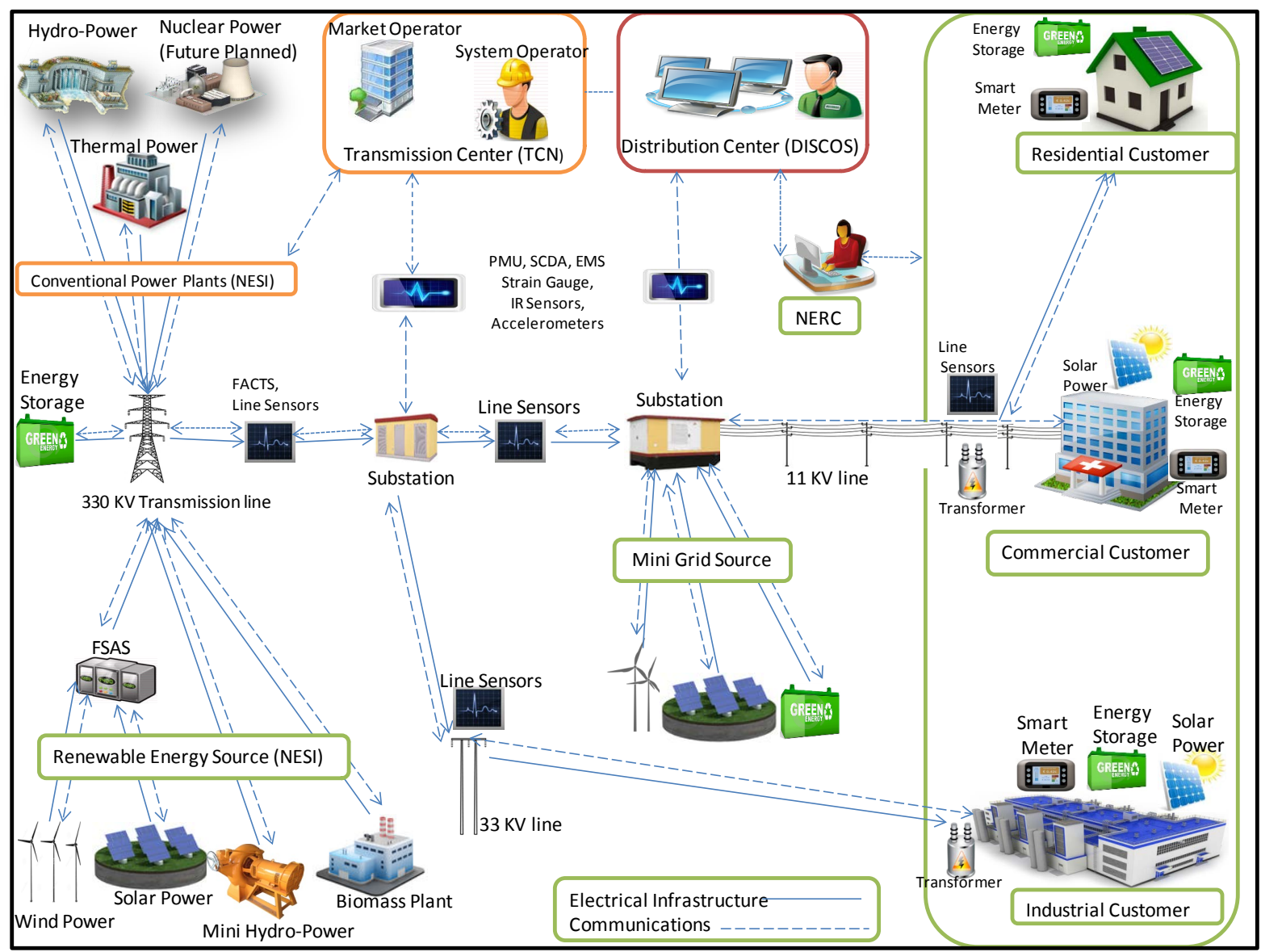

Figure 7. The proposed smart grid system.

\subsection{Energy Policy Overview}

We will now have a brief overview of the existing policies and required plans on energy to enable us identify the reforms of policy objectives, gaps and options that are unavoidable if Nigeria is to achieve a secure access to renewable energy which will be integrated with the proposed smart grid into the Nigerian grid system.

The National Energy Policy (NEP) of 2006 sets out government policy on the production, supply and consumption of energy reflecting the perspective of its overall needs and options. The main goal of the policy is to create energy security through a robust energy supply mix by diversifying the energy supply and energy carriers based on the principle of "an energy economy in which modern renewable energy increases its share of energy consumed and provides affordable access to energy throughout Nigeria, thus contributing to sustainable development and environmental conservation" [23]. Importantly, the national policy already outlines the key elements for development and application of renewable energy as:

- To promote decentralized energy supply, especially in rural areas, based on RE resources

- To develop, promote and harness Renewable Energy (RE) resources of the country and incorporate all viable ones into the national energy mix

- To promote efficient methods in the use of biomass energy resources

- To de-emphasize and discourage the use of wood as fuel

- To keep abreast of international developments in RE technologies and applications.

In an effort to translate the RE component of the NEP into an actionable plan, the Energy Commission of Nigeria (ECN) in 2005 developed the Renewable Energy Master Plan (REMP) to complement the NEP, which reiterated the government's pledge to support the development, demonstration and implementation of RE sources for both small and large applications. To create the appropriate enabling environment for the promotion of RE, the REMP identified the need for appropriate financial and legal instruments, technology development, awareness 
raising, capacity building and education as the strategic areas to be paid attention and further sets specific goals for each of those areas [9] [11].

The REMP aims at a 10\% RE contribution to the national energy mix by 2020 through the adoption of a renewable portfolio standard (RPS). A RPS is a requirement for electric utilities to supply a specific amount of electricity to customers. This can be achieved through the purchase of renewable energy certificates from suppliers with a larger share of renewables in their energy mix. Other measures considered are the creation of innovative fiscal and market incentives to grow renewable energy industries, as well as preferential customs duty exemptions for imported renewable energy technology components [9] [11].

However, the lack of implementation of the master plan has meant that the $10 \%$ target of renewable energy mix in the energy supply cannot be achieved. The REMP is presently being subjected to a review, likely resulting in the setting of new targets. It will be essential that any future targets set for the attainment of a RE energy mix should be backed by legislation to ensure compliance, which is presently lacking. Similarly, the National Policy and Guidelines on Renewable Electricity was produced in 2006 with the main aim to expand the market for renewable electricity by $5 \%$ of the total electricity generation by 2016. The strategy for achieving this target included: encouraging local manufacture and assembly of renewable energy components, provision of subsidies, and establishment of technical standards for RE components and introduction of feed-in-tariffs. The strategy is yet to be fully adopted as the reforms in the energy sector are still ongoing and decisions on tariffs and subsidies for renewable energy and other incentives have not yet been taken [11].

The Energy Commission also developed a draft National Energy Master Plan (NEMP) in 2006. The NEMP acknowledged the imminent dangers of the fossil fuel driven economy, its global environmental concerns and the expediency of adopting a less carbon intensive and environmentally friendly development pathway, and recommended urgent action to diversify the economy and create a sustainable energy supply mix. A National Gas Master Plan of 2008 envisages a wholesale transition to decentralized privately held electricity generation gas plants from the erstwhile public power utility. The plan also aims to stem the huge waste associated with gas flaring and to put to more productive use the nation's large gas reserves. What the Gas Master Plan does not clearly mention is that the utilization of Compressed Natural Gas (CNG) can play a major role in transforming the nation's transportation sector if adopted on a large scale. Clear benefits are evident, for example in the Lagos State Bus Rapid System (BRT), which recorded a 13\% reduction in $\mathrm{CO}_{2}$ and $20 \%$ in other greenhouse gas emissions [24].

The Nigerian Atomic Energy Commission was established to explore Nigeria's nuclear energy potentials for peaceful purposes. Given the expected expansion of electricity demands by the growing population, the ECN has called for an activation of a Nigerian nuclear programme and the Nigerian Atomic Energy Commission is already undertaking preliminary steps [9]. This is however curious when considered against the background that the Vision 2020 does not include atomic energy in its proposed energy mix. After the nuclear accident in Fukushima, Japan, and given the long-term huge costs of producing atomic power, pursuing the nuclear path seems like an outdated strategy. Even though nuclear is said to contribute $16 \%$ of global electricity, high cost and liabilities, major safety and waste management issues, exacerbated by the weak regulatory environment, make nuclear energy less attractive for the timely provision of energy access to the poor. Unsurprisingly, countries like Germany are gradually abandoning nuclear energy [9] [24].

\subsection{Benefits of Smart Grid Technology}

There are various ways Nigeria and her citizens can benefit from the proposed integration of smart grid technology [18]:

- The smart grid will accommodate all generation and storage options. It will seamlessly integrate many types of electrical generation and storage systems with a simplified interconnection process analogous to "plug and play" technology of the retail computer industry

- Optimizes asset utilization and operating efficiency. A smart grid applies the latest technologies to optimize the use of its assets. For example, optimized capacity can be attainable with dynamic ratings, which allow assets to be used at greater loads by continuously sensing and rating their capacities.

- The smart grid will ensure the level of power quality desired by the users. New power quality standards will balance load sensitivity with delivered power quality at a reasonable price. The modernized grid will supply varying grades of power quality at different pricing levels. Not all commercial enterprises, and certainly not all residential customers, need the same quality of power. A smart grid supplies varying grades (and prices) 
of power.

- The grid will heal itself. The modernized grid will perform continuous self-assessments to detect, analyze, respond to and as needed, restore grid components or network sections. It will handle problems too large or too fast moving for human intervention. Acting as the grid’s “immune system”, self-healing will help maintain grid reliability, security, affordability, power quality and efficiency.

- The smart grid will resist attack. Security requires a system-wide solution that will reduce physical and cyber vulnerabilities and recovers rapidly from disruptions. Both its design and its operation will discourage attacks, minimize their consequences and speed service restoration. Resiliency refers to the ability of a system to react to unexpected events by isolating problematic elements while the rest of the system is restored to normal operation. These self-healing actions result in reduced interruption of service to consumers and help service providers better manage the delivery infrastructure.

- The modern grid will enable markets to flourish. Open-access markets expose and shed inefficiencies. The modern grid will enable more market participation through increased transmission paths, aggregated demand response initiatives and the placement of energy resources including storage within a more reliable distribution system that is closer to the consumer.

- It will motivate consumers to be an active grid participant and will include them in grid operations. In the modernized grid, well-informed consumers will modify consumption based on the balancing of their demands and the electric system's capability to meet those demands. Demand for new cost-saving and energy-saving products will benefit both the consumer and the power system. Consumers help balance supply and demand, and ensure reliability by modifying the way they use and purchase electricity. These modifications come as a result of consumers having choices that motivate different purchasing patterns and behavior. These choices involve new technologies, new information about their electricity use, and new forms of electricity pricing and incentives [18].

\section{Policy Recommendation and Conclusion}

\subsection{Policy Recommendation}

Some policy recommendation and are given on the short, mid and long term in order to facilitate proper integration of renewables and smart grid into the Nigerian electricity grid;

\section{1) Energy Data}

\section{Short term}

- Off-grid power production study of small and large generators, rural electrification projects not connected to the national grid, private homes with solar PV installations.

Result will show areas that needs connection to the national grid and can also support the national grid during peak hours.

- Nationwide power consumption study on residential, service and industries. Result will show consumption pattern in regions that are off-grid and on-grid.

- Intensive study on renewable energy resources available in the country.

Result will show regions of the country with their most promising renewable energy.

- Establishment of a National Energy Databank which should be up-to-date.

This will aid the government agency, local and international organization to properly analyze energy situation in Nigeria.

$\underline{\text { Mid term }}$

- Acurate availability of a National Energy Databank.

\section{2) Energy Efficiency}

For a proper power management society.

Short term

Introduce and promote:

- Energy education programs in schools, service and industrial sectors.

- Efficiency standards on home, office and industrial appliances and equipment.

- Phase out old energy consuming appliances and electric bulbs with new low energy saving bulbs.

- Replace the old metering still in use in some part of the country to pre-paid Smart meters.

- Create incentives for electricity retailers and utility companies. 
Mid term

- Mandatory energy education programs in all the educational levels in Nigeria.

- Complete and mandatory use of low energy consuming appliances, electric bulbs and equipment in homes, offices and industries.

- Incentives for final electricity consumers.

\section{3) Grid-Connected Power}

Short term

- Employ movable gas turbines like Single Cycle Gas Turbines (SCGTs) and Combine Cycle Gas Turbines (CCGTs).

- Conduct feasibility studies for $100 \mathrm{MW}$ pilot projects from wind, solar and small hydropower.

- Introduce and encourage micro-grid operators.

- Proper maintenance of power generating facilities including hydropower.

- Proper security of transmission and distribution equipment. Mid term

- Expand CCGTs electricity generation capacity.

- Build $100 \mathrm{MW}$ demonstration projects for grid connected wind, solar PV and small hydropower.

\section{4) Off-Grid Power}

\section{$\underline{\text { Short term }}$}

Introduce, subsides and encourage:

- Solar PV for irrigation, water pumping and lighting.

- Solar PV with battery storage for homes.

- Use natural gas to replace diesel by the use of small gas powered turbines of up to $5 \mathrm{MW}$. Mid term

- Promote solar PV and small gas turbines for off-grid and micro-grid.

- Introduce and promote small hydropower plants.

\section{5) Integrated Planning Process}

\section{Short term}

- Develop a comprehensive electricity system analysis of all generating plants (both current and future planned), transmission networks and distribution centers in order to develop long term plans.

- Consider setting of renewables during grid expansion e.g. during power plant site selection and transmission line expansion, potential renewable energy should be put in mind for integration on the mid and long term. Mid term

- Integrate planning of CCGTs and more power plants into the national grid.

- Encourage integration of distributed generation into the national grid.

- Introduce wide area monitoring and control device into the national grid.

- Total upgrade of transmission lines and equipment, introduction of transmission enhancement.

6) Policies

Short term

- Allow domestic fossil fuels prices revert to global market prices.

- Allow tariffs to fully reflect in electricity costs.

- Promote CCGT and convert existing SCGTs to CCGTs.

- Introduce policy framework that promotes off-grid renewables; Feed-in-tariffs (FITs), renewable portfolio standards (RPS), and renewable energy certificate (RECs).

- Introduce degree courses on renewable energy and smart grid technology in Nigerian Universities.

- Develop R\&D centers on renewable energy and smart grid technology.

- Build demonstration and training projects on renewable energy.

- Develop proper financial mechanisms on renewables like low interest loans and Clean Development Mechanism (CDM).

Short term

- Build small scale pilot projects on smart mini grid technology.

- Government gradually withdraws and private sectors take over.

Long term

Develop a nationwide smart grid connected network. 


\subsection{Conclusion}

In this paper, we have observed that the Nigerian electricity grid is faced with a lot of problems which include the insufficient and inefficient power generation facilities, inadequately maintained long transmission lines and distribution facilities, and outdated metering system used by its customers. The integration of smart grid technology and renewables into the Nigerian electricity grid system remains the only solution to the electricity crisis in the country. We have shown that the smart grid technology is possible in Nigeria through the various technological integrations, enhancement and policy recommendation given in this paper. The benefits of the smart grid technology will not only improve electricity production and efficiency in Nigeria, but will also enable electricity consumers to become producers of electricity and enhance Nigeria's international competiveness. Limitation in this paper includes analysis like cost benefit analysis, Feed-in-Tariffs (FITs), Renewable Portfolio Standards (RPS), Renewable Energy Certificate (REC) which were not discussed in order to determine the best policy mechanism for renewable energy and smart grid integration in Nigeria, therefore this limitation should be addressed in subsequent research.

\section{References}

[1] Sambo, A.S. (2009) Strategic Developments in Renewable Energy in Nigeria. International Association for Energy Economics, 16.

[2] Worldbank Databank. http://www.tradingeconomics.com/nigeria/access-to-electricity-percent-of-population-wb-data

[3] Koledoye, T.O., Abdul-Ganiyu, J.A. and Phillips, D.A. (2013) The Current and Future Challenges of Electricity Market in Nigeria in the Face of Deregulation Process. African Journal of Engineering Research, 1, 33-39.

[4] KPMG Nigeria: A Guide to the Nigerian Power Sector, December 2013.

[5] Sambo, A.S., Garba, B., Zarma, I.H. and Gaji, M.M. (2003) Electricity Generation and the Present Challenges in the Nigerian Power Sector. Energy Resources Review, 4, 7-10.

[6] Patrick, O., Tolulolope, O. and Sunny, O. (2013) Smart Grid Technology and Its Possible Applications to the Nigeria 330 kV Power System. Smart Grid \& Renewable Energy, 4, 391.

[7] Sunday, O.O. and Friday, O.O. (2010) Empirical Modelling of Power Losses as a Function of Line Loadings and Lengths in the Nigerian 330 kV Transmission Lines. International Journal of Academic Research, 2, 47-53.

[8] Nigeria Population. http://www.cia.gov/library/publications/the-world-factbook/geos/ni

[9] (2005) Energy Commission of Nigeria: 1st Energy Lecture Series.

[10] Aniefiok, E., Igweonu, I.E., Eguzo, C.V. and Robert, B.J. (2013) Integrating Smart Grid Model in Nigeria Power Network. International Journal of Advances in Engineering \& Technology, 6, 1760-1768.

[11] Mshelia, I.H. (2012) Energy Access for All: The Role of Clean Energy in Alleviating Energy Poverty. http://us.boell.org/2012/05/18/green-deal-nigeria-greening-economy

[12] The Nigerian Yearly Average of Daily Sun. www.geni.org

[13] Akpu, I.V. Renewable Energy Potentials in Nigeria. Internation Association for Impact Assessment.

[14] Nigeria Wind Energy. http://www.neenigeria.com/Nigeria wind NEW.png

[15] Nigeria Water Ways. http://www.safety4sea.com/

[16] Giordano, V. and Bossart, S. (2012) Accessing Smart Grid Benefits and Impacts: EU and U.S Initiatives.

[17] U.S. Department of Energy (DOE) (2009) The Modern Grid System, A Vision for the Smart Grid. National Energy Technology Laboratory.

[18] IEA (2011) Technology Road Map on Smart Grids. International Energy Agency.

[19] (2009) Oracle White Paper: Smart Grids-Strategic Planning and Development.

[20] Smart Grid by PDHengineer.com, Course No. E-5006. http://www.pdhengineer.com/page-not-found-404/

[21] (2013) Integrating Wind and Solar Energy in India for a Smart Grid Platform, Global Energy Network Institute (GENI).

[22] (2009) Integration of Demand-Side Management, Distributed Generation, "Renewable Energy Sources and Energy Storages”, International Energy Agency Demand-Side Management Programme (Ieadsm), Finland.

[23] (2006) National Energy Policy (NEP). www.energy.gov.ng

[24] Eleri, E., Ugwu, O. and Onuvae, P. (2011) Low-Carbon Africa: Leapfrogging to Green Future: Low Carbon Africa: Nigeria. www.christainaid.org/uk/resources/policy/climate/low-carbon-africa 
Scientific Research Publishing (SCIRP) is one of the largest Open Access journal publishers. It is currently publishing more than 200 open access, online, peer-reviewed journals covering a wide range of academic disciplines. SCIRP serves the worldwide academic communities and contributes to the progress and application of science with its publication.

Other selected journals from SCIRP are listed as below. Submit your manuscript to us via either submit@scirp.org or Online Submission Portal.
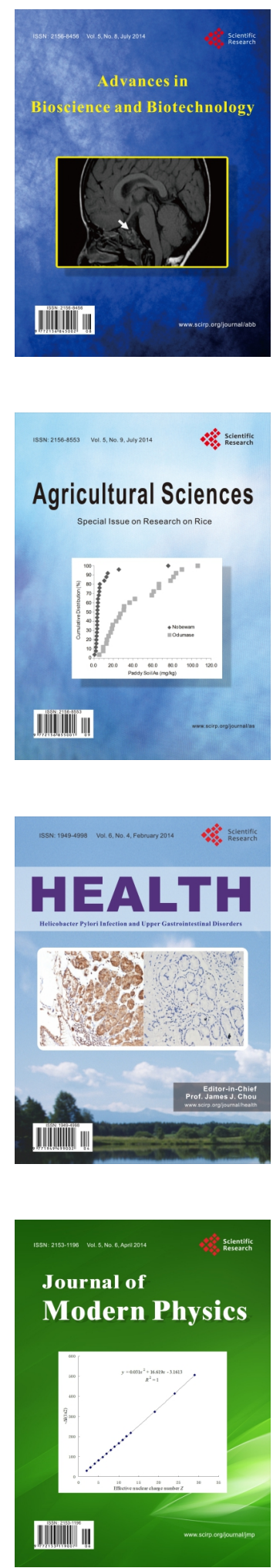
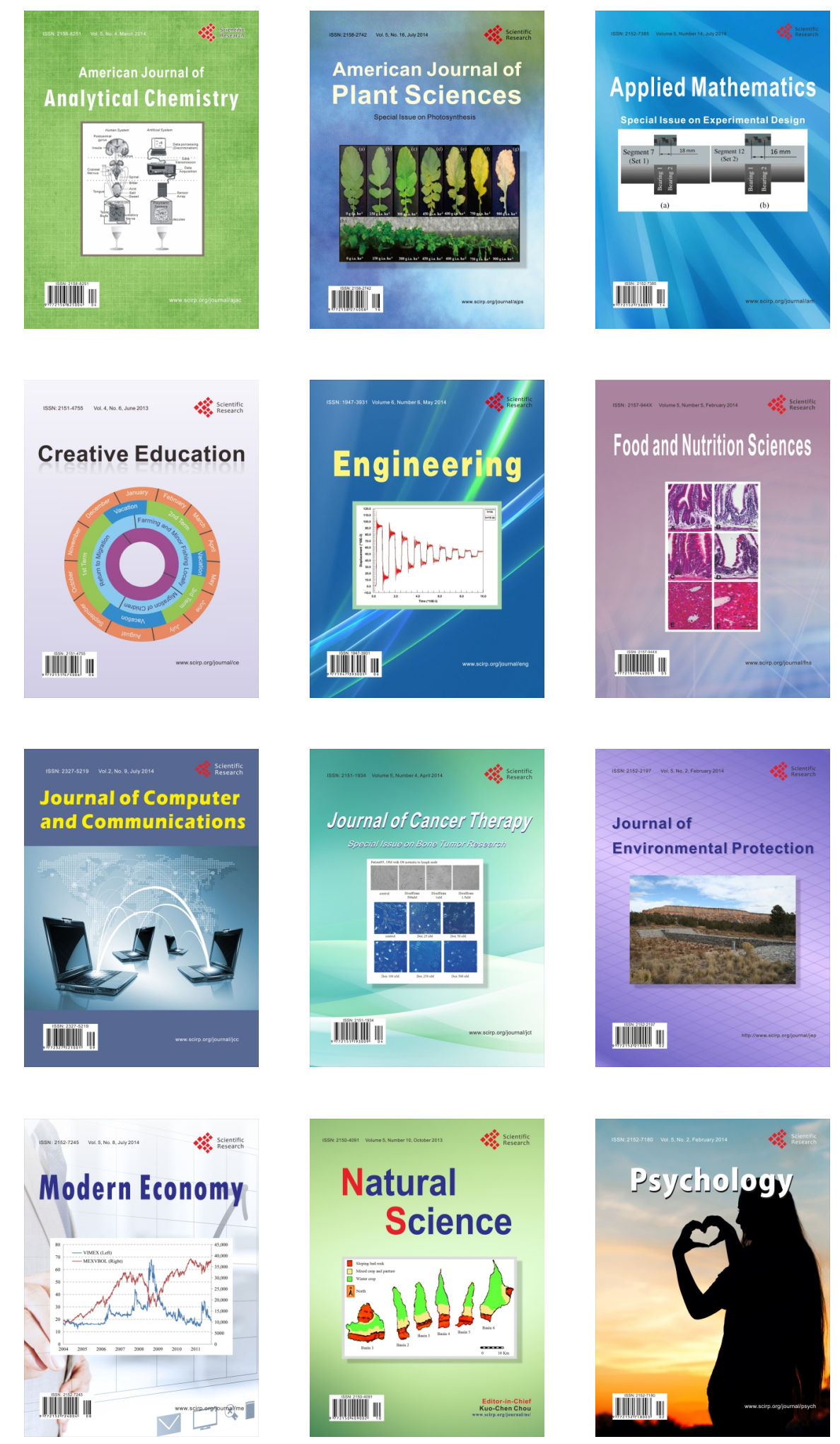